\title{
Epidemiology of familial adenomatous polyposis in Finland: impact of family screening on the colorectal cancer rate and survival
}

\author{
H J Järvinen
}

\begin{abstract}
The incidence and prevalence rates of familial adenomatous polyposis (FAP) in Finland between 1961 and 1990 were estimated from Finnish polyposis registry data comprising 81 FAP families, including 251 affected patients. In addition, the effect of family screening on the occurrence of colorectal carcinoma was evaluated by comparing the call up and proband groups and calculating the proportion of FAP among all patients with colorectal carcinoma. The incidence of FAP was 0.62 to 2.38 per million and the prevalence increased steadily from 0.88 to 26.3 million during the study period suggesting improving prognosis. Altogether 76 of 116 probands $(65.5 \%)$ had colorectal carcinoma compared with only five of 76 call up patients $(6 \cdot 6 \%)$. Consequently, the life expectancy of the call up patients was significantly better than that of the probands from the age of $\mathbf{3 1}$ years and above. However, at most, $0.53 \%$ of all colorectal carcinomas were associated with FAP in 1966-70, and the diminishing frequency of this proportion was more a result of an increase in sporadic colorectal carcinomas in Finland than of family screening for FAP. Family screening is very effective in FAP and must always be undertaken when a new proband is diagnosed.
\end{abstract}

Familial adenomatous polyposis (FAP) is one of the best known hereditary cancer traits, a Mendelian autosomal dominant condition in which the development of the otherwise inevitable colorectal carcinoma can be anticipated and prevented by appropriate prophylactic screening and treatment. ${ }^{12}$ FAP is relatively uncommon, but estimates of its frequency are mainly based on indirect calculations from restricted regional samples and vary from 1 per 6850 to 1 per 30000 people. ${ }^{13-6}$ An accurate estimate of the incidence and prevalence of FAP requires well organised data collection over a long period from a sufficiently large and well defined region with accurate general population data. These requirements are met in the Nordic countries where FAP registries have been established for over 10 to 30 years. Thus far, there has been only one nationwide epidemiological study based on direct patient data and this was from Denmark. ${ }^{7}$ In this study the incidence was about 1 per million people with a temporary rise up to 2 per million when effective screening was started. The frequency corresponded to about 1 in 10000 and agreed with the indirect observations from Sweden. ${ }^{4}$

In this study the epidemiology of FAP in
Finland was calculated on the basis of patient data from the Finnish polyposis registry, established in $1980 .{ }^{8}$ In addition, the importance of family screening was evaluated in two different ways. Firstly, the proportion of FAP patients among all patients with colorectal cancer was determined using the statistics of the Finnish cancer registry. Secondly, the life expectancies of the FAP patients diagnosed through family screening (call up patients) were compared with those of patients diagnosed when symptoms had occurred (probands).

\section{Methods}

PATIENTS

By the end of March 1991, the Finnish polyposis registry had data on about 81 separate Finnish FAP families, with a total of 251 affected patients. These consisted of 76 call up patients identified during family screening and 116 probands diagnosed as symptomatic irrespective of whether or not other affected family members had already been treated. The remaining 59 cases were assumed FAP patients - that is, first degree relatives of FAP patients with a verified colorectal cancer but no confirmation of the underlying adenomatosis. The source of the patient data have been described earlier, ${ }^{8}$ and they are similar to those in the Danish registry. ${ }^{\text {? }}$

The call up group consisted of 40 men and 36 women with a mean age of $26 \cdot 8$ years at the time of diagnosis (range nine to 60 years). This group was followed up for a median of 8.5 years (range six months to 22.5 years), and 60 patients underwent prophylactic colectomy (or proctocolectomy). One patient died of periampullary cancer before this operation and 15 asymptomatic patients still await the prophylactic operation. In the proband group there were 56 men and 60 women with a mean age of 40.0 years when diagnosed (range 17 to 80 years). All have been operated on or have died of cancer. The median follow up time was 5.5 years after the diagnosis (range three months to 27.5 years).

TABLE I Mean yearly incidence rates for familial adenomatous polyposis $(F A P)$ in Finland over five year periods from 1961-90.

\begin{tabular}{llll}
\hline Period & $\begin{array}{l}\text { Mean population } \\
\times 10^{\circ}\end{array}$ & $\begin{array}{l}\text { FAP cases per } \\
\text { 5years }\end{array}$ & $\begin{array}{l}\text { Incidencelyear per } \\
\text { million people }\end{array}$ \\
\hline $1961-65$ & 4.52 & 14 & 0.62 \\
$1966-70$ & 4.63 & 29 & 1.25 \\
$1971-75$ & 4.67 & 21 & 0.91 \\
$1976-80$ & 4.75 & 47 & 1.98 \\
$1981-85$ & 4.87 & 58 & 2.38 \\
$1986-90$ & 4.95 & 39 & 1.58 \\
\hline
\end{tabular}

Finland

Dr Jarvinen, Second

Helsinki University Centra

Hospital, SF-00290 Helsinki,

Accepted for publication

3 June 1991 


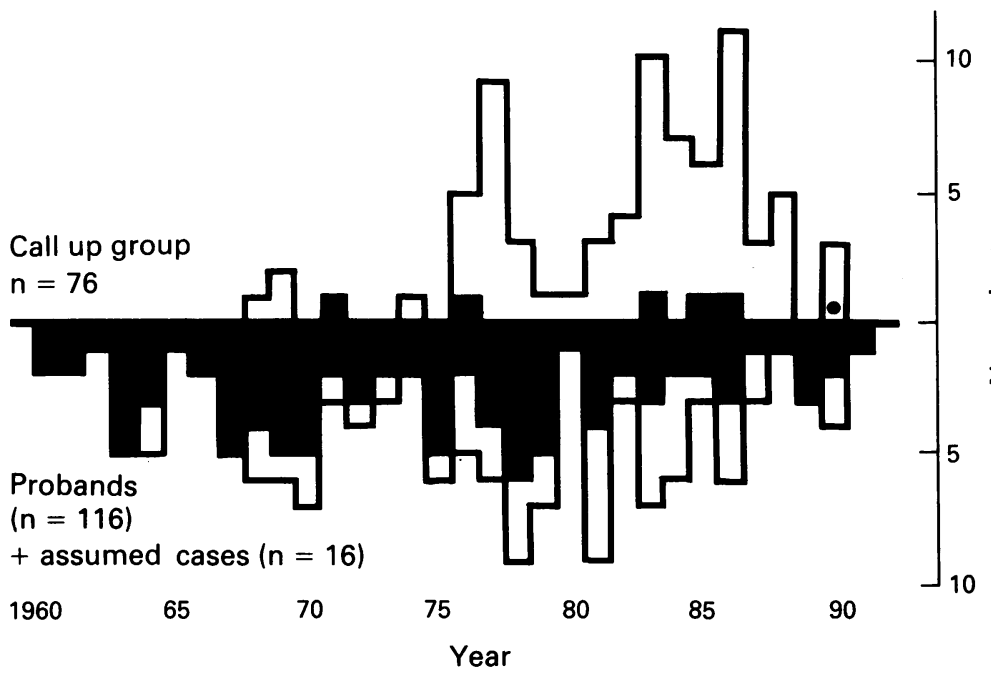

Figure 1: Patients with familial adenomatous polyposis diagnosed in Finland between 1960 and 1991 year by year. Black areas represent patients with colorectal carcinoma at the time of diagnosis: white areas those with no cancer. One 10 year old boy was diagnosed by 1990 by genetic linkage analyses (black spot); sigmoidoscopy not yet performed.

Patients with assumed FAP (33 men and 26 women) had died of colorectal cancer at a mean age of $53 \cdot 2$ years.

STATISTICAL METHODS AND POPULATION DATA The yearly incidence (mean for five-year periods) and prevalence (at the end of each five-year period) rates for FAP were determined for the period 1961-90 and included 16 assumed cases within these years. The population data of Finland were received from the Finnish Statistical Office. 'The frequency of FAP was also estimated indirectly according to Alm and Licznerski as follows: ${ }^{4}$

Frequency $=P / D$

where $\mathbf{P}=$ patients with $\mathrm{FAP}$ dying in a period and $\mathrm{D}=$ all deaths in the same period. The frequency was further calculated according to the number of FAP patients born in the 10 year periods from 1930-69 and compared with all live births within the same periods; the latter figures were reduced by $3 \%$ to eliminate those who died at a younger age than 20 years $^{9}$ when the diagnosis of FAP is unlikely without screening.

The proportion of colorectal carcinoma caused by underlying FAP was determined for the five year periods from 1961-90 using yearly occurrence rates for colorectal cancer derived from the Finnish cancer registry, ${ }^{10}$ including unpublished case numbers for the years after 1989. The frequencies of colorectal carcinoma in FAP patients call up and proband groups were compared $\left(\chi^{2}\right.$ test) and the life expectancies of these two groups were estimated using the Kaplan-Maier life table analysis. The significance of the difference was tested with the MantelHaenszel log rank test.

\section{Results}

\section{EPIDEMIOLOGY OF FAP}

FAP patients in Finland were first diagnosed reliably and subsequently treated adequately in 1963 , even though family studies had disclosed
TABLE II Prevalences of familial adenomatous polyposis $(F A P)$ at the end of each five year period from 1961-90 in Finland

\begin{tabular}{llcl}
\hline Period & $\begin{array}{l}\text { Population } \times 10^{\circ} \text { at } \\
\text { end of period }\end{array}$ & $\begin{array}{l}\text { No of FAP } \\
\text { patients }\end{array}$ & $\begin{array}{l}\text { Prevalencel } \\
\text { million people }\end{array}$ \\
\hline $1961-65$ & $4 \cdot 56$ & 4 & $0 \cdot 88$ \\
$1966-70$ & $4 \cdot 61$ & 19 & $4 \cdot 12$ \\
$1971-75$ & $4 \cdot 72$ & 26 & $5 \cdot 52$ \\
$1976-80$ & $4 \cdot 78$ & 56 & $11 \cdot 7$ \\
$1981-85$ & 4.91 & 92 & $19 \cdot 0$ \\
$1986-90$ & 4.99 & 130 & $26 \cdot 3$ \\
\hline
\end{tabular}

TABLE III Estimates of the frequency of familial adenomatous polyposis (FAP) deaths in Finland in 10-year periods from 1960-89 and among those born between 1930 and 1969

\begin{tabular}{llll}
\hline & $\begin{array}{l}\text { No of FAP } \\
\text { patients died/ } \\
\text { born }\end{array}$ & $\begin{array}{l}\text { All deaths or } \\
\text { births }\end{array}$ & Frequency $\times 10^{-5}$ \\
Period & & & \\
\hline Deaths: & 23 & 430614 & $5 \cdot 34=1: 18720$ \\
$1960-69$ & 30 & 442154 & $6 \cdot 78=1: 14738$ \\
$1970-79$ & 21 & 457625 & $4 \cdot 59=1: 21790$ \\
$1980-89$ & 39 & 693772 & $5 \cdot 62=1: 17800$ \\
Births & 42 & 867096 & $4 \cdot 84=1: 21300$ \\
$1930-39$ & 35 & 869290 & $4 \cdot 03=1: 24840$ \\
$1940-49$ & 33 & 758767 & $4 \cdot 35=1: 22990$ \\
$1950-59$ & $1960-69$ & 35 &
\end{tabular}

* Total birth rates reduced by $3 \%$ to eliminate those dying before the age of 20 years, when diagnosis of FAP is unlikely without screening.

TABLE IV Proportion of colorectal carcinoma caused by underlying familial adenomatous polyposis $(F A P)$ among all cases of colorectal cancer in Finland in five year periods from 1961-90

\begin{tabular}{llll}
\hline Period & $\begin{array}{l}\text { No of FAP } \\
\text { patients with } \\
\text { cancer }\end{array}$ & $\begin{array}{l}\text { All cases of } \\
\text { colorectal } \\
\text { cancer }\end{array}$ & $\begin{array}{l}\text { Mean annual } \\
\text { proportion of } \\
\text { FAP cases (\%) }\end{array}$ \\
\hline $1961-65$ & 12 & 3300 & $0 \cdot 36$ \\
$1966-70$ & 21 & 3975 & $0 \cdot 53$ \\
$1971-75$ & 15 & 4915 & $0 \cdot 31$ \\
$1976-80$ & 19 & 6010 & $0 \cdot 32$ \\
$1981-85$ & 15 & 7100 & $0 \cdot 21$ \\
$1986-90$ & 11 & $8000^{\star}$ & $0 \cdot 14$ \\
\hline
\end{tabular}

^The exact case numbers for the years 1989 and 1990 are not yet available; estimates are used instead.

TABLE v Causes of death in the verified familial adenomatous polyposis $(F A P)$ patients from the call up group $(n=76)$ and the proband group $(n=116)$

\begin{tabular}{lr}
\hline Call up patients & 1 \\
Carcinoma of the stomach & 1 \\
Periampullary carcinoma of the pancreas & 50 \\
Proband group: & 1 \\
Disseminated colorectal carcinoma & 1 \\
Polypous bile duct carcinoma & 2 \\
Adrenal carcinoma & 2 \\
Postoperative complications (pulmonary embolism; & 1 \\
bowel occlusion) & Myocardial infarction \\
Suicide(10 years after colectomy)
\end{tabular}

some colorectal cancer patients with apparently underlying polyposis in the early 1940s. Thus, the mean yearly incidence rate was only 0.62 per million in the first half of the 1960 s rising to about 1 per million for $1966-75$, and then reached the present rate of 1.58 to 2.38 per million after systematic family screening examinations started (Table I). The proportions of FAP patients diagnosed by family screening were $0,10,9 \cdot 5,40,52$, and $56 \%$ in the successive five year periods from 1961-90 respectively (Fig 1).

The point prevalence at the end of each five year period increased from 0.88 per million in 


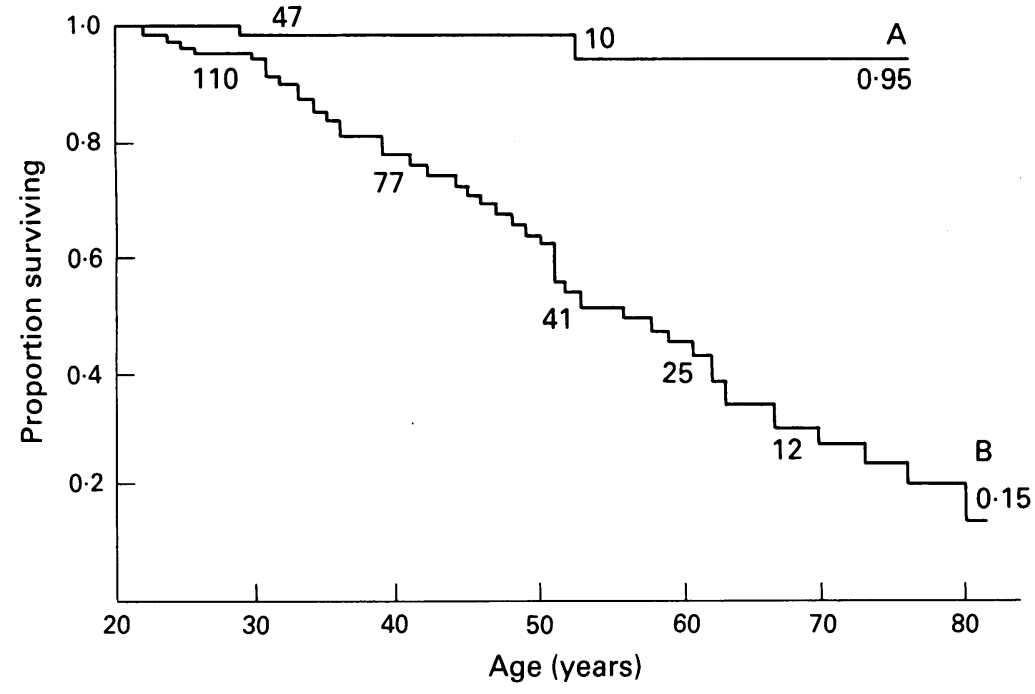

Figure 2: Lifetime cumulative survival analysis (Kaplan-Maier) of patients with familial adenomatous polyposis: $A=$ call-up group $(n=76), B=$ probands $(n=116)$. The figures at the curves indicate the number of patients in each group remaining in follow up.

1965 to $26 \cdot 3$ million in 1990 (Table II), reflecting the improved prognosis of FAP. At present, 130 registered FAP patients are living in Finland; 74 of them are call-up patients and 56 probands.

For comparison, indirect estimates of the frequency of FAP in people dying between 1960 and 1989, and in those born between 1930 and 1969, are shown in Table III. In these calculations the highest frequency was one in 14740 and the lowest one in 24800 .

FAP AND THE COLORECTAL CANCER RATE

Of all verified FAP patients, $81(42 \cdot 2 \%)$ had colorectal carcinoma at the time of diagnosis; 76 of 116 probands $(65.5 \%)$ and five of 76 call-up patients $(6.6 \%)$ who were diagnosed by family screening $(p<0.001)$. The proportions of colorectal carcinomas caused by FAP during the five year periods from 1961-90 of all new colorectal carcinomas in Finland are shown in Table IV. The highest rate was $0.53 \%$ in $1966-70$ and the lowest $0 \cdot 14 \%$ in $1986-90$ (see also Fig 1 ).

\section{IMPORTANCE OF FAMILY SCREENING}

The importance of family screening on the life expectancy of FAP patients is shown in Figure 2 which compares the cumulative survival of patients diagnosed by screening with that of the proband group. The life expectancy of the call up group was significantly better $(p<0.001)$ from the age of 31 years on. Two and 57 FAP patients in the two groups, respectively, have died during follow up. The causes of death are listed in Table $\mathrm{V}$ and show that colorectal carcinoma was by far the most common cause of untimely death in FAP. There were also two deaths in each group caused by extracolonic malignancies. No deaths have been observed because of desmoid tumours occurring in nine call up patients and 13 probands.

\section{Discussion}

Familial adenomatous polyposis (FAP) seems to occur at a relatively constant frequency overall in the world, irrespective of differences in the incidence of sporadic colorectal carcinoma. Thus, the incidence of FAP in Finland, which is between 1.58 and 2.38 per million at present, corresponds to that of Denmark ${ }^{7}$ despite the fact that the incidence of colorectal cancer in Finland $\left(18 / 10^{5}\right)$ was only half that of the incidence in Denmark in $1980 .{ }^{10}$ Similarly, estimates based on indirect calculations have given almost identical frequencies for FAP in England and Japan, one in 23900 and one in 22000 respectively, even though colorectal cancer is common in England and relatively rare in Japan. ${ }^{56}$ The observed incidence rate predicts that 5-10 new FAP patients will be detected every year in Finland (population five million people), while the calculations on the basis of death rates give lower estimates. Obviously, the improving prognosis of FAP reflected in the increasing prevalence rates - makes indirect calculations more and more biased.

That family screening should always be undertaken when a new proband with FAP was diagnosed was reasonably clear, even before Bussey collected the extensive data of the first polyposis registry at St Mark's Hospital:' in his series the frequency of colorectal cancer was $66.2 \%$ in the probands but only $9.4 \%$ in the call up patients. Similar differences in the frequencies of cancer in favour of the call up groups have been observed in many other registry series, ${ }^{11-13}$ and the result was the same in this study: $65 \cdot 5 \%$ of the probands had cancer compared with $6 \cdot 6 \%$ of the call up patients. These figures show that colorectal carcinoma can be prevented in most cases by prophylactic examination and subsequent preventative surgery; in theory prevention is always possible if screening is done in time.

The present follow up study shows for the first time, that the life expectation of the call up patients is comparable with that of the general population. The cumulative survival curves of the call up and proband groups already differed significantly at the age of 31 years. In a corresponding cumulative analysis Bülow ${ }^{11}$ also showed the clear advantage of screening from the time of diagnosis, but this method ignored the age difference at diagnosis which was about 14 years in his series. It is noteworthy in the present study that even the five patients in the call up group who already showed carcinoma in the colectomy specimen are all still alive more than five years after surgery.

On the other hand, the relatively short average follow up time (median 8.5 years) may give too optimistic an impression of screening. There were after all deaths from upper gastrointestinal carcinoma (stomach, periampullary cancer) in call up patients, and two other extracolonic cancers in the probands. Two further cases of duodenal carcinoma have been treated, one in each group, and in one case several liver metastases developed later after pancreaticoduodenectomy. Duodenal and sometimes other upper gastrointestinal adenomas have been found in up to $50 \%$ of patients with FAP,,$^{1+15}$ and their progression to carcinoma seems to be a matter of a real concern. ${ }^{16}$ Therefore, regular 
endoscopic surveillance of the stomach and duodenum has to be stressed, even though the efficacy of its value remains to be shown in prospective studies. Other long term concerns may be the increased frequencies of desmoid tumours $^{1217}$ and of rectal stump carcinomas after ileorectal anastomosis, ${ }^{18}$ but there were no deaths from these complications in this series.

There are other problems that may result in less than optimal long term results despite family screening. One important aspect is to convince the newly diagnosed call up patients of the importance of prophylactic surgery. Fifteen of the Finnish patients in this study still await the operation and most of them attend for check ups, but some have refused further cooperation or are afraid of the operation. There are two examples of at risk people who refused screening examinations despite repeated requests, and who subsequently died of disseminated colorectal carcinoma at the ages of 31 and 47 years.

The impact of FAP on the frequency of colorectal carcinoma as a whole remains small, less than $1 \%$ as was suggested by Mulvihill. ${ }^{19}$ The present study shows that the highest proportion of FAP among all cases of colorectal cancer in Finland was $0.53 \%$ in the years 1966-70, when family screening was not yet arranged. At present the corresponding proportion is $0 \cdot 14 \%$, when slightly more than half of all FAP patients have been detected by family screening. It might be concluded that most of this decrease is caused by the increasing tendency of sporadic colorectal cancer in Finland, and that the impact of family screening for FAP would be only marginal. This small effect, however, is a question of life and death for the at risk members of FAP families who have a $50 \%$ risk of developing colorectal cancer unless treated in time, and is a good enough reason for continuing the activity of the centralised Finnish polyposis registry and for establishing new registries elsewhere.
This work was supported by the Finnish Foundation for Gastroenterology.

1 Bussey HJR. Familial polyposis coli. Family studies, histopathology, differential diagnosis and results of treatment. pathology, differential diagnosis and results of treatm

2 Neale K, Ritchie S, Thomson JPS. Screening of offspring of patients with familial adenomatous polyposis: the St. Mark's Hospital Polyposis Register experience. In: Herrera L, ed. Familial adenomatous polyposis. New York: Alan R Liss, 1990: 61-6.

3 Pierce ER. Some genetic aspects of familial multiple polyposi of the colon in a kindred of 1422 members. Dis Colon Rectum 1968; 5: 321-9.

4 Alm T, Licznerski G. The intestinal polyposes. Clin Gastroenterol 1973; 2: 577-602.

5 Utsunomiya J, Iwama T. Adenomatosis coli in Japan. In: Winawer S, Schottenfeld D, Sherlock P, eds. Colorectal cancer: prevention, epidemiology and screening. New York: cancer: prevention, epidemi

6 Veale AMO. Intestinal polyposis. Eugenics Laboratory Memoirs Series 40. London: Cambridge University Press, 1965.

7 Bülow S, Holm NV, Hauge M. The incidence and prevalence of familial polyposis coli in Denmark. Scand F Soc Med 1986; 14: $67-74$

8 Järvinen HJ, Husa A, Aukee S, Matikainen M, Havia T. Finnish registry for familial adenomatosis coli. Scand $\mathfrak{f}$ Gastroenterol 1984; 19: 941-9.

9 Central Statistical Office of Finland. Statistical yearbook of Finland. Vol 84 (new series). Helsinki: Valtion painatuskeskus, 1989.

10 Hakulinen T, Andersen AA, Malker B, Pukkala E, Schou G, Tulinius H. Trends in cancer incidence in the Nordic countries. A collabrative study of the five Nordic Cancer Registries. Helsinki: The Nordic Cancer Registries, 1986. Helsinki: The Nordic Cancer Registries, 1986

11 Bülow S. Clinical features in familial polyposis coli. Results of the Danish Polyposis Register. Dis Colon Rectum 1986; 29. 102-7.

12 Vasen HFA, Griffioen G, Offerhaus GJA, et al. The value of screening and central registration of families with familial adenomatous polyposis. Dis Colon Rectum 1990; 33: 227-31.

3 Alm T. Surgical treatment of hereditary adenomatosis of the colon and rectum in Sweden during the last 20 years. Part II. Patients with prophylactic operations, primary and late results. Acta Chir Scand 1975; 141: 228-37.

14 Watanabe H, Enjoii M, Yao T, Ohsato K. Gastric lesions in familial adenomatosis coli. Hum Pathol 1978; 9: 269-83.

15 Järvinen H, Nyberg M, Peltokallio P. Upper gastrointestinal tract polyps in familial adenomatosis coli. Gut 1983; 24: 3339.

16 Jagelman DG, Bussey HJR, DeCosse JJ, The Leeds Castle Polyposis Group. Upper gastrointestinal cancer in familial Polyposis Group. Upper gastrointestinal cancer

17 Jones IT, Jagelman DG, Fazio VW, Lavery IC, Weakley FL, McGannon E. Desmoid tumors in familial polyposis coli. Ann Surg 1986; 204: 94-7.

18 Bess MA, Adson MA, Elveback LR, Moertel CG. Rectal cancer following colectomy for polyposis. Arch Surg 1980; 115: 460-7.

19 Mulvihill JJ. The frequency of hereditary large bowel cancer. In: Ingall JRF, Mastromarino AJ, eds. Prevention of hereditary large bowel cancer. New York: Alan R Liss inc, $1983 ; 61-75$. 